\title{
Pathogenetic substantiation of the combined transplantation use of multipotent mesenchymal stromal cells and hepatic stellate cells to restore the liver morphofunctional state after acute toxic hepatitis in the old body
}

\author{
Irina Maklakova ${ }^{1,2 *}$, Dmitry Grebnev ${ }^{1,2}$, Victoria Vakhrusheva ${ }^{1}$, and Ilya Gavrilov ${ }^{1,2}$ \\ ${ }^{1}$ FSBEI HE Ural State Medical University Ministry of Health of the Russian Federation, 620028, \\ Yekaterinburg, Russian Federation \\ ${ }^{2}$ SAHI SO "Institute of Medical Cell Technologies", 620026, Yekaterinburg, Russian Federation
}

\begin{abstract}
The purpose of this study was to study the cotransplantation influence of multipotent mesenchymal stromal (MMSC) and hepatic stellate (HSC) cells on liver regeneration of old laboratory animals in conditions of its toxic damage. Acute toxic hepatitis was caused by single intraperitoneal CCl4 injection at a dose of $50 \mu \mathrm{g} / \mathrm{kg}$. The introduction of MMSC and HSC was carried out at doses of 4 million $\mathrm{cl} / \mathrm{kg}$ and 9 million $\mathrm{cl} / \mathrm{kg}$ respectively 1 hour after toxic hepatitis modelling. The morphofunctional liver state of old laboratory mice was evaluated on the 1st, 3rd, 7th day after combined injection of MMSC and HSC in laboratory animals with toxic hepatitis. As a result of the study, it was obtained that MMSC and HSC cotransplantation leads to cellular and intracellular liver regeneration activation in old mice with acute toxic hepatitis. Also, the introduction of these cell types leads to decreased liver mutagenesis, inhibition of programmed cellular hepatocytes death. Thus, the conducted studies indicate the ability of combined MMSC and HSC transplantation to restore the morphofunctional liver state of the old organism under the conditions of its toxic damage.
\end{abstract}

\section{Introduction}

Statistics data analysis from the Ministry of Health of the Russian Federation, the Department of Monitoring, Analysis and Strategic Development of Health, as well as the World Health Organization for 2018 show an increase in the number of patients with liver pathology [1]. Therapeutic approaches currently used in the treatment of liver failure remain ineffective. This makes finding new methods capable of activating regeneration in a damaged organ relevant.

\footnotetext{
${ }^{*}$ Corresponding author: makliu@mail.ru
} 
This study examined the ability of two types of stem cells - hepatic stellate cells (HSC) and multipotent mesenchymal stromal cells (MMSC) to activate liver regeneration in conditions of its toxic damage through the carbon tetrachloride introduction. The choice of these types of stem cells was due to their biological properties. Currently, hepatic stellate cells are seen as contenders for the role of liver stem cell by a number of authors [2,3]. Their ability to differentiate into hepatocytes, cholangiocytes [3, 4] is shown. Hepatic stellate cells provide synthesis of subendothelial extracellular matrix, which regulates hepatocyte function, produce a wide range of cytokines that increase hepatocytes proliferative activity: hepatocytic growth factor (HGF), stem cell factor (SCF), epimorphine, pleiotrophin. Expressing VCAM-1 and SDF-1 $\alpha$ HSC, they provide migration of autologous stem and progenitor cells including MMSC to the liver. MMSC can be compared to the "factory" for biologically active substances production. Thus, synthesized MMSC immunosuppressive factors (TGF- $\beta$, IL-10) provide the possibility of allogenic transplantation, significantly reducing the probability of immunological conflicts development $[5,6,7,8]$. The ability of MMSC through formation of intercellular contacts to induce the production of heat-shock proteins with molecular weight of $70 \mathrm{kD}$ (chaperones) in cells $[9,10,11]$ has been proved. This group of proteins supports the conformation of structural and functional proteins. Given these biological relationships between MMSC and HSC, it seems promising to study the effect of combined transplantation of these cell types on liver regeneration in conditions of its damage.

It is known that during aging there is not only a decrease in the stem cells number, a decrease in differentiation ability, but also a decrease in their sensitivity to physiologically active substances $[12,13,14]$. This can determine the characteristics of liver regeneration in the conditions of its toxic damage during aging.

The purpose of this study was to study the MMSC and HSC combined transplantation effect on the liver regeneration of old laboratory animals in the conditions of its toxic damage.

\section{Materials and methods of research}

Experiments were performed on 84 white male laboratory mice 16-17 months of age, mass - 25-30 g. MMSC was released from the placenta chorion of 5 female laboratory mice aged 3-4 months, gestation period - 18 days. All experiments, care and management of animals were carried out in accordance with Directive No. 63 dated September 22, 2010 of the Presidency and the Parliament of Europe "On the Protection of Animals Used for Scientific Research" and the Order of the Ministry of Health of the Russian Federation No. 267 of June 19, 2003 "On approval of the rules of laboratory practice". The research is approved by the local ethical committee of FSBEI HE "Ural State Medical University" Protocol No. 8 dated 20.10.2017.

The mononuclear cell fraction was obtained by sequential mechanical and enzymatic (solution of accutase (Millipore, USA)) processing of placenta tissue. The MMSC immunophenotype is characterized by: CD105+, Sca1+, CD29+, CD45- [10]. Immunophenotyping of MSSC suspension was carried out by flow cytometry method using monoclonal antibodies conjugated with fluorochromes (Becton Dickinson, USA). The MMSC content with immunophenotype positive by CD105, CD29, Sca-1 and negative by CD45 was evaluated in the fraction of transplantable cells on the Beckman Coulter Navios flow cytometer using the Mouse Mesenchymal Stem CellMulti-Color Flow Cytometry Kit (Bio-Techne, USA). The number of viable cells with the CD45-, CD105+, Sca1+, CD29+ phenotype was $93.5 \%$. The HSC release was carried out by collagenase-pronase liver perfusion method followed by cell separation in histogenesis density gradient. The MMSC was cultivated under $\mathrm{CO}_{2}$ conditions - an incubator (Termo Scientific, USA) at a 
temperature of $37^{\circ} \mathrm{C}$ with $5 \%$ carbon dioxide content and $90 \%$ humidity. The MMSC of the third passage was used for transplantation to laboratory animals. The HSC introduction was carried out immediately after cells isolation.

The study of isolated cells functional properties was carried out by directed differentiation of the obtained culture in directions characteristic of MMSC - in adipocytic and osteogenic. The HSC identification was performed on the Beckman Coulter Navios flow cytometer by evaluating HSC endogenous retinoid fluorescence. The cell viability was determined by supravital coloration with a solution of tripan blue and amounted to 95 $-97 \%$.

Experimental group animals were intravenously injected with MMSC and HSC at a dose of 4 million cells $/ \mathrm{kg}$ and 9 million cells $/ \mathrm{kg}$ respectively, suspended in $0.2 \mathrm{ml} 0.9 \%$ $\mathrm{NaCl}$ solution. The control group animals were injected with $0.9 \%$ solution of $\mathrm{NaCl}-0.2$ $\mathrm{ml}$ intravenously. Intravenous injection was performed 1 hour after the simulation of acute toxic hepatitis. Toxic hepatitis was caused by intraperitoneal injection of $\mathrm{CCl} 4$ at a dose of $50 \mu \mathrm{g} / \mathrm{kg}$.

The influence of MMSC and HSC combined transplantation on biochemical parameters of peripheral blood and morphometric liver parameters under physiological conditions and after subtotal resection on the $1 \mathrm{st}, 3 \mathrm{rd}$, 7 th day. The animals were taken out of the experiment with decapitation under mild ethereal anesthesia.

Histological liver cuts 3-5 $\mu \mathrm{m}$ thick stained with hematoxylin-eosin was made. For morphometric data analysis a computer program of image analysis (Biovision, Russia) was used. The following liver morphometric indicators were evaluated: hepatocyte count per 1 $\mathrm{mm}^{2}$, hepatocyte area, hepatocyte nucleus area, hepatocyte cytoplasm area, nuclear cytoplasmic index (NCI), number of binuclear hepatocytes per $1 \mathrm{~mm}^{2}$, mitotic index (MI), apoptotic index (AI). Verification of apoptosis severity was carried out using the ApopTag® Peroxidase In Situ Oligo Ligation (ISOL) (Millipore, USA) method.

The evaluation of peripheral blood biochemical indicators was performed on the automatic biochemical and immunoenzyme analyzer Chem Well 2910 (Combi). The following biochemical indicators were studied: total protein, albumin, urea, glucose, total bilirubin, aspartataminotransferase (AST), alaninaminotransferase (ALT), alkaline phosphatase (ALP). "Olvex Diagnosticum" (Russia) kits were used in determining biochemical indicators. Determination of fibrinogen concentration was carried out on the hemostasis indicators analyzer APG2-02-P.

Statistical data processing was carried out using the SPSS Statistics software package (version 17.0). The data is represented as arithmetic mean $(\mathrm{M})$ and standard mean error (m). The sample values distribution normality was estimated on the Shapiro-Wilk test. If there is a normal distribution, the differences estimation in group indicators was conducted according to the Student t-criterion, otherwise -the Mann-Whitney U-criterion. The differences were considered statistically significant at $\mathrm{p}<0.05$.

\section{Study results}

On the 1st day after MMSC and HSC combined transplantation to old laboratory mice with toxic hepatitis, no reliable differences between experimental and control groups were found.

In the study of morphometric liver indicators of old laboratory animals 3 days after the carbon tetrachloride introduction, animals injected with MMSC and HSC had a decrease in apoptosis levels and increasing number of biconuclear hepatocytes. There was also an increase in the hepatocytes' nucleus area and a consequent increase in the nuclear cytoplasmic index. In the analysis of the hepatocytes micronuclei number there was a decrease observed compared to the control group (table 1). 
Table 1. Morphometric liver indicators of old laboratory mice 3 days after $\mathrm{CCl}_{4}$, $\mathrm{M} \pm \mathrm{m}$ injection, $\mathrm{n}=7$

\begin{tabular}{|c|c|c|c|}
\hline Indicators & Intact animals & \multicolumn{2}{|c|}{ Animals with toxic hepatitis } \\
\cline { 2 - 4 } & $\mathrm{NaCl}$ & $\mathrm{NaCl}$ & MMSC+HSC \\
\hline Number of hepatocytes per $1 \mathrm{~mm}^{2}$ & $1323.14 \pm 111.31$ & $1431.29 \pm 116.33$ & $1552.43 \pm 125.06$ \\
\hline Area of hepatocytes, $\mu \mathrm{m}^{2}$ & $297.10 \pm 21.14$ & $228.04 \pm 17.47^{*}$ & $242.26 \pm 19.45^{*}$ \\
\hline Hepatocyte nucleus area, $\mu \mathrm{m}^{2}$ & $57.60 \pm 5.37$ & $70.54 \pm 5.34^{*}$ & $87.51 \pm 7.87^{*} * *$ \\
\hline Area of hepatocyte cytoplasm, $\mu \mathrm{m}^{2}$ & $239.93 \pm 16.42$ & $157.50 \pm 15.14^{*}$ & $154.74 \pm 12.92^{*}$ \\
\hline NCI & $0.25 \pm 0.02$ & $0.45 \pm 0.03^{*}$ & $0.57 \pm 0.03^{* * *}$ \\
\hline $\begin{array}{c}\text { Number of binuclear hepatocytes per } \\
\mathrm{mm}^{2}\end{array}$ & $241.06 \pm 21.38$ & $736.14 \pm 56.37^{*}$ & $913.86 \pm 85.84^{* * *}$ \\
\hline MI, \%o & $0.40 \pm 0.05$ & $6.80 \pm 0.51^{*}$ & $7.53 \pm 0.71^{*}$ \\
\hline AI, \%o & $0.51 \pm 0.04$ & $4.34 \pm 0.39^{*}$ & $3,41 \pm 0.24^{* * *}$ \\
\hline $\begin{array}{c}\text { Number of hepatocytes with } \\
\text { micronucleus, \%o }\end{array}$ & $3.20 \pm 0.20$ & $8.43 \pm 0.62^{*}$ & $6.04 \pm 0.59^{* * *}$ \\
\hline
\end{tabular}

Note: * reliable with $\mathrm{p}<0.05$ unlike the intact group of old laboratory animals $* *$ reliable with $\mathrm{p}<0.05$ unlike the control group of old laboratory animals.

In the morphometric indicators' analysis of laboratory mice on the 7th day after carbon tetrachloride introduction, increased mitotic index and decreased apoptosis severity were noted in the experimental group. Also, after combined MMSC and HSC injection, an increase in the hepatocyte nuclei area was found, which contributed to the increase of the nuclear cytoplasmic index. In addition, there was an increase in the number of binuclear hepatocytes compared to the control group. Analyzing the number of cytogenetically altered cells, their decrease in comparison with the data of the control group was observed (Table 2).

Table 2. Morphometric liver indicators of laboratory mice on the 7th day after $\mathrm{CCl}_{4}$ injection, $\mathrm{M} \pm \mathrm{m}, \mathrm{n}=7$

\begin{tabular}{|c|c|c|c|}
\hline \multirow{2}{*}{ Indicators } & Intact animals & \multicolumn{2}{|c|}{ Animals with toxic hepatitis } \\
\cline { 2 - 4 } & $\mathrm{NaCl}$ & $\mathrm{NaCl}$ & MMSC+HSC \\
\hline Number of hepatocytes per $1 \mathrm{~mm}^{2}$ & $1296.29 \pm 119.84$ & $1408.86 \pm 117.88$ & $1333.86 \pm 92.12$ \\
\hline Area of hepatocytes, $\mu \mathrm{m}^{2}$ & $293.69 \pm 21.25$ & $225.73 \pm 19.00^{*}$ & $279.31 \pm 22.44^{* *}$ \\
\hline Hepatocyte nucleus area, $\mu \mathrm{m}^{2}$ & $59.41 \pm 4.44$ & $76.80 \pm 6.74^{*}$ & $108.81 \pm 13.31^{*} * *$ \\
\hline Area of hepatocyte cytoplasm, $\mu \mathrm{m}^{2}$ & $234.27 \pm 19.12$ & $148.93 \pm 14.02^{*}$ & $170.50 \pm 11.40^{*}$ \\
\hline NCI & $0.25 \pm 0.02$ & $0.52 \pm 0.02^{*}$ & $0.64 \pm 0.05^{* * *}$ \\
\hline $\begin{array}{c}\text { Number of binuclear hepatocytes } \\
\text { per mm }\end{array}$ & $239.71 \pm 21.30$ & $471.43 \pm 30.49^{*}$ & $618.86 \pm 58.78^{* * *}$ \\
\hline MI, \%o & $0.38 \pm 0.05$ & $7.37 \pm 0.40^{*}$ & $9.10 \pm 0.60^{* * *}$ \\
\hline AI, \%o & $0.51 \pm 0.04$ & $4.60 \pm 0.31^{*}$ & $3.47 \pm 0.40^{* * *}$ \\
\hline $\begin{array}{c}\text { Number of hepatocytes with } \\
\text { micronucleus, \% }\end{array}$ & $3.19 \pm 0.21$ & $8.57 \pm 0.74^{*}$ & $5.97 \pm 0.48^{* * *}$ \\
\hline
\end{tabular}

Note: * reliable with $\mathrm{p}<0.05$ unlike the intact group of old laboratory animals $* *$ reliable with $\mathrm{p}<0.05$ unlike the control group of old laboratory animals.

Thus, it was identified that combined MMSC and HSC transplantation to old laboratory mice under toxic hepatitis conditions leads to activation of cellular and intracellular regeneration. Combined MMSC and HSC introduction led to a decrease in programmed cell death. The decrease in the number of hepatocytes with micronuclei in laboratory animals following the MMSC and HSC introduction indicates the ability of these cells to reduce induced mutagenic activity in the liver under toxic hepatitis conditions. 
In the biochemical parameters' analysis of laboratory mice peripheral blood on the 3rd day after carbon tetrachloride introduction against the background of combined MMSC and HSC transplantation, a decrease in enzymes content characterizing hepatocyte cytolysis: AST, ALT (table 3) was observed.

Table 3. Biochemical blood indicators of laboratory mice on the 3rd day after $\mathrm{CCl}_{4}$ injection, $\mathrm{M} \pm \mathrm{m}, \mathrm{n}=7$

\begin{tabular}{|c|c|c|c|}
\hline \multirow{2}{*}{ Indicators } & Intact animals & \multicolumn{2}{|c|}{ Animals with toxic hepatitis } \\
\cline { 2 - 4 } & $\mathrm{NaCl}$ & $\mathrm{NaCl}$ & MMSC+HSC \\
\hline Total protein, $\mathrm{g} / \mathrm{l}$ & $73.39 \pm 4.42$ & $50.14 \pm 4.04^{*}$ & $52.99 \pm 4.16^{*}$ \\
\hline Albumin, $\mathrm{g} / \mathrm{l}$ & $26.76 \pm 2.21$ & $17.86 \pm 1.71^{*}$ & $19.24 \pm 1.64^{*}$ \\
\hline Urea, $\mathrm{mmol} / \mathrm{l}$ & $6.20 \pm 0.43$ & $6.08 \pm 0.53$ & $5.79 \pm 0.49$ \\
\hline Glucose, $\mathrm{mmol} / \mathrm{l}$ & $5.93 \pm 0.36$ & $4.28 \pm 0.34^{*}$ & $4.55 \pm 0.31^{*}$ \\
\hline Total bilirubin, $\mu \mathrm{mol} / \mathrm{l}$ & $10.07 \pm 0.46$ & $13.61 \pm 1.09^{*}$ & $12.69 \pm 1.21^{*}$ \\
\hline AST, Un/L & $102.73 \pm 7.83$ & $180.85 \pm 11.76^{*}$ & $141.91 \pm 12.74^{* * *}$ \\
\hline ALT, Un/L & $92.87 \pm 7.19$ & $210.95 \pm 12.18^{*}$ & $160.55 \pm 13.54^{* * *}$ \\
\hline Alkal. Phosphatase, $\mathrm{Un} / \mathrm{L}$ & $78.61 \pm 5.82$ & $125.46 \pm 10.07^{*}$ & $115.23 \pm 9.11^{*}$ \\
\hline Fibrinogen, $\mathrm{g} / \mathrm{l}$ & $3.80 \pm 0.23$ & $2.49 \pm 0.19^{*}$ & $2.63 \pm 0.21^{*}$ \\
\hline
\end{tabular}

Note: * reliable with $\mathrm{p}<0.05$ unlike the intact group of old laboratory animals $* *$ reliable with $\mathrm{p}<0.05$ unlike the control group of old laboratory animals.

In the analysis of the peripheral blood biochemical parameters on the 7th day after the combined MMSC and HSC transplantation against the carbon tetrachloride introduction background, there was a noticeable decrease in the level of AST to values of intact animals, decrease in ALT levels, increase in fibrinogen (table 4) .

Table 4. Biochemical blood indicators of laboratory mice on the 7th day after $\mathrm{CCl}_{4}$ injection, $\mathrm{M} \pm \mathrm{m}, \mathrm{n}=7$

\begin{tabular}{|c|c|c|c|}
\hline \multirow[t]{2}{*}{ Indicators } & Intact animals & \multicolumn{2}{|c|}{ Animals with toxic hepatitis } \\
\hline & $\mathrm{NaCl}$ & $\mathrm{NaCl}$ & MMSC+HSC \\
\hline Total protein, $\mathrm{g} / \mathrm{l}$ & $72.24 \pm 4.32$ & $54.05 \pm 4.80^{*}$ & $57.68 \pm 4.11^{*}$ \\
\hline Albumin, g/l & $27.34 \pm 1.99$ & $19.06 \pm 1.71 *$ & $19.89 \pm 1.79 *$ \\
\hline Urea, mmol/l & $6.27 \pm 0.65$ & $6.53 \pm 0.60$ & $6.16 \pm 0.56$ \\
\hline Glucose, $\mathrm{mmol} / \mathrm{l}$ & $5.79 \pm 0.44$ & $4.51 \pm 0.44^{*}$ & $4.61 \pm 0.32 *$ \\
\hline Total bilirubin, $\mu \mathrm{mol} / 1$ & $10.13 \pm 0.62$ & $13.06 \pm 1.34 *$ & $12.64 \pm 1.02 *$ \\
\hline $\mathrm{AST}, \mathrm{Un} / \mathrm{L}$ & $101.19 \pm 8.41$ & $143.78 \pm 10.28^{*}$ & $111.50 \pm 9.48^{* *}$ \\
\hline ALT, Un/L & $95.57 \pm 7.36$ & $177.60 \pm 12.98^{*}$ & $123.68 \pm 11.83 * * *$ \\
\hline Alkal. Phosphatase, Un/L & $75.56 \pm 5.11$ & $103.04 \pm 9.10 *$ & $93.56 \pm 7.91 *$ \\
\hline Fibrinogen, g/l & $3.80 \pm 0.26$ & $2.50 \pm 0.17 *$ & $3.00 \pm 0.20 * *$ \\
\hline
\end{tabular}

Note: * reliable with $\mathrm{p}<0.05$ unlike the intact group of old laboratory animals $* *$ reliable with $\mathrm{p}<0.05$ unlike the control group of old laboratory animals.

\section{Conclusions}

Conducted studies indicate the ability of combined MMSC and HSC transplantation to activate liver regeneration in the old body under the conditions of its toxic damage. Regeneration activation is achieved through the inclusion of cellular (mitotic activity increase) and intracellular mechanisms (increased number of binuclear hepatocytes, increased nuclear-cytoplasmic index). Regeneration activation may be due to the ability of 
HSC to produce growth factors, as well as the ability of MMSC to merge - "fusion-effect". The data obtained also show that introduction of cell species provides reduced mutagenesis and inhibition of programmed cell death. The apoptosis inhibition can be explained by the MMSC ability to induce the production of heat-shock proteins (chaperones) in liver cells through the formation of intercellular contacts. Heat-shock proteins provide stability to structural and functional proteins including reparation enzymes. Thus, the cell gains additional opportunities to repair damage in the DNA molecule structure, resulting in a decrease in programmed cell death and a decrease in the amount of cytogenetically altered cells.

Thus, the conducted studies indicate the ability of combined MMSC and HSC transplantation to restore the morphofunctional liver state of the old organism under the conditions of its toxic damage.

\section{References}

1. Russian statistical yearbook. Stat.sb., Rosstat - P 76, 694 (M., 2018)

2. A. A. Gumerova, A. K. Shafigullina, A. A. Trondin, I. M. Gazizov, D. I. Andreeva, M. S. Kaligin, A. A. Rizvanov, A. P. Kiasov, Cell transplantology and tissue engineering, 6 (4), $72-81$ (2011)

3. C. Kordes, I. Sawitza, S. Gotze, D. Herebian, Journal of Clinical Investigation, 124 (12), 5503-5515 (2014)

4. C. Yin, K. J. Evason, K. Asahina, D. Y. Stainier, Journal of Clinical Investigation, 123 (5), 1902-1910 (2013)

5. J. Jung, J. Choi, Y. Lee [et al.], Stem cells, 31, 1584-1596 (2013)

6. I. Y. Maklakova, D. Y. Bulletin of Experimental Biology and Medicine, 163 (1), 61-64 (2017)

7. D. J. Prockop, J. Y. Oh, Mol. Ther., 20 (1), 14-20 (2012)

8. A. A. Brilliant, Yu. M. Brilliant, S. V. Sazonov, European Journal of Cancer, 49 (S2), $216(2013)$

9. R. M. Samsonraj, M. Raghunath, V. Nurcombe, [et al.], Stem Cells Transl. Med., 6 (12), 2173 (2017)

10. S. F. H. de Witte, M. Franquesa, C. C. Baan, M. J. Hoogduijn, Frontiers in Immunology, 6, 648 (2016)

11. N. Pilat, L. Unger, G. A. Berlakovich, Hindawi Publishing Corporation International Journal of Hepatology, 7, (2013) Article ID 310612; http:/ /dx.doi.org/10.1155/2013/310612.

12. N. A. Timchenko, Trends in Endocrinology \& Metabolism, 4 (20), 171-176 (2009)

13. R. A. B. Nucci, A. C. S. Teodoro, E. F. Gama, Morphol. Sci, 33 (4), 179-182 (2016)

14. G. K. Michalopoulos, J. Cell Physiol, 213 (2), 286-300 (2007) 